\title{
Retraction Note to: Traffic identification and traffic analysis based on support vector machine
}

\author{
Youchan $\mathrm{Zhu}^{1} \cdot \mathrm{Yi}_{\mathrm{Z}} \mathrm{Zheng}^{1}$
}

Received: 1 September 2021 / Accepted: 1 September 2021 / Published online: 9 September 2021

(C) Springer-Verlag London Ltd., part of Springer Nature 2021

\section{Retraction Note to: Neural Computing and Applications (2020) 32:1903-1911 \\ https://doi.org/10.1007/s00521-019-04493-2}

The Editor-in-Chief has retracted this article because it shows significant overlap with a previously published article by Zhongshen et al. [1].

Dr Y. Zhu does not agree to this retraction and Dr. Zheng has not responded to any correspondence from the publisher about this retraction.

The original article has been retracted.

\section{Reference}

1. Zhongsheng W, Jianguo W, Sen Y, Jiaqiong G (2020) RETRACTED: Traffic identification and traffic analysis based on support vector machine. Concurr Comput Pract Exp 32:e5292. https://doi.org/10.1002/cpe.5292

Publisher's Note Springer Nature remains neutral with regard to jurisdictional claims in published maps and institutional affiliations.

The original article can be found online at https:// doi.org/10.1007/s00521-019-04493-2.

Youchan Zhu

40550998@ncepu.edu.cn

Yi Zheng

2609625875@qq.com

1 School of Control and Computer Engineering, North Chinese Electric Power University, Baoding, China 